\title{
Analysis and Evaluation of Factors Affecting the Use of Google Classroom in Albania: A Partial Least Squares Structural Equation Modelling Approach
}

\author{
Evgjeni Xhafaj $^{1, *}$, Daniela Halidini Qendraj ${ }^{2}$, Alban Xhafaj ${ }^{3}$, Etleva Halidini $^{4}$ \\ ${ }^{1}$ Department of Mathematics, Faculty of Mathematics and Physics Engineering, Polytechnic University of Tirana, Albania \\ ${ }^{2}$ Department of Mathematics, Faculty of Information Technology, University "Aleksander Moisiu” Durres, Albania \\ ${ }^{3}$ Data Scientist and BI platforms at INTRUM ITALY, S.p.A, Tirana, Albania \\ ${ }^{4}$ Department of Mathematics, General High School "Besnik Sykja", Albania
}

Received December 15, 2020; Revised February 22, 2021; Accepted March 12, 2021

\section{Cite This Paper in the following Citation Styles}

(a): [1] Evgjeni Xhafaj, Daniela Halidini Qendraj, Alban Xhafaj, Etleva Halidini , "Analysis and Evaluation of Factors Affecting the Use of Google Classroom in Albania: A Partial Least Squares Structural Equation Modelling Approach," Mathematics and Statistics, Vol. 9, No. 2, pp. 112 - 126, 2021. DOI: 10.13189/ms.2021.090205.

(b): Evgjeni Xhafaj, Daniela Halidini Qendraj, Alban Xhafaj, Etleva Halidini (2021). Analysis and Evaluation of Factors Affecting the Use of Google Classroom in Albania: A Partial Least Squares Structural Equation Modelling Approach. Mathematics and Statistics, 9(2), 112 - 126. DOI: 10.13189/ms.2021.090205.

Copyright $\mathrm{C} 2021$ by authors, all rights reserved. Authors agree that this article remains permanently open access under the terms of the Creative Commons Attribution License 4.0 International License

\begin{abstract}
The study explores the number of factors that affect the use of Google Classroom in Albanian universities, by using the methodological developments of partial least squares structural equation modelling technique (PLS- SEM). This technique has been used because it allows flexibility in modelling the relationship between constructs (or factors) and in exploring theoretical concepts. An alternative model is introduced by extending the Unified Theory of Acceptance and Use of Technology (UTAUT2) and by integrating new relation between constructs. Our data are from a study of 528 students from 4 Albanian universities during the year 2020. Using Importance-Performance Matrix Analysis (IPMA) our analysis suggest that Habit is the construct that has the greatest importance in determining the Behavioral Intention towards Google Classroom, whereas Behavioral Intention has the greatest importance related to Use Behavior of Google Classroom. The results of the study show that Habit, and Hedonic Motivation have a greater impact on the Behavioral Intention to use Google Classroom. Additionally, we find that all constructs of the alternative model have an important influence to Behavioral Intention to Google Classroom and explain 65.3 per cent of its variance. This study will help the Higher Educations Institutions in assessing the factors that influence the use of Google Classroom, in such a way that
\end{abstract}

this platform should be used as a support tool in the future.

Keywords Google Classroom, Partial Least Squares Structural Equation Modeling (PLS-SEM), Albanian Universities, UTAUT2.

\section{Introduction}

Due to the situation created by Covid-19, the traditional way of teaching and learning, (i.e. face to face) in Albanian universities, moved towards e-learning tools, achieved through the implementation of the Learning Management Systems (LMSs). LMS are web-based systems that allow users such as instructors and /or students to share materials, submit, return assignments, and interact online with each other [1]. Recently the number of LMS is rapidly growing, among them is mentioned Google Classroom being the most popular tool to be integrated into higher education [2]. The Google Classroom platform was introduced in 2014 as part of the $\mathrm{G}$ suite for Education. In terms of interaction for teaching and learning, Google Classroom is convenient and simple because it allows interactions between other web-based applications such as Gmail, Google Drive, Google Docs, 
Google Calendar and Google Hangout. Additionally students prefer Google Classroom compared to other LMS platforms because it is a free mobile application, easy to learn, and they can sign in from any computer or mobile device to access class assignments, course materials, and feedback, mobile application notifications. It is important for each university that before implementing e-learning tools to know the user acceptance of a new technology, i.e. what students need and accept [3]. There are various models that analyze the acceptance of these technologies namely, Theory of Reasoned Action (TRA) proposed by Fishbein M, Ajzen I [4], Technology Acceptance Model (TAM) by Davis FD [5], Unified Theory of Acceptance and Use (UTAUT) created by Venkatesh V. [6]. The later model was developed further into the Unified Theory of Acceptance and Use of Technology (UTAUT2) [7].

\subsection{The UTAUT2 Model}

The model UTAUT2 explains the technology acceptance and use [7]. UTAUT2 considers various constructs (factors) : Performance Expectancy (PE), Effort Expectancy (EE), Social Influence (SI), Facilitating Conditions (FC), Hedonic Motivation (HM), Habit (HT) and Price Value, whereas UTAUT includes only the first 4 constructs. The UTAUT2 model shows that the factors PE, EE, SI, FC, HM are predictors of BI, and the factors FC, $\mathrm{BI}, \mathrm{HT}$ are predictors of UB (See figure 1)

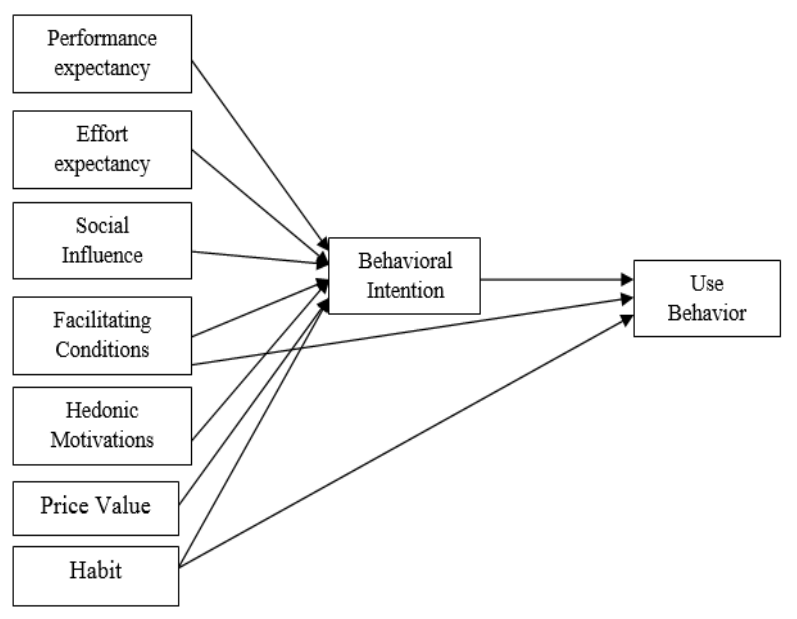

Figure 1. The Unified Theory of Acceptance and Use of Technology 2 (UTAUT2) [7]

$\mathrm{PE}$ is defined as the student's belief that using Google Classroom is useful in learning productivity. EE is defined as the level of ease of use for Google Classroom. SI is defined as the degree of student's influence by close friends, regarding the issue that the use of Google Classroom is important in the learning process. FC indicates the confidence degree in technical support when using Google Classroom. HM defines the satisfaction of using Google Classroom in relation to traditional learning [8].
HT is related with the automatic behavior of students using the Google Classroom platform. BI indicates student's intention in using Google Classroom in the future. In the study of Jakkaew , Hemrungrote [3], the UTAUT2 model is used to explain the factors that influence the acceptance of the Google Classroom platform. Through Pearson's correlation the findings show that the factors PE, EE, SI, FC, HM and have a positive relationship on the Behavioral Intention to use Google Classroom. Kumar JA [2] used PLS-SEM in the model modified by UTAUT2 to analyse how the constructs of the latter affect each other; the results point towards the fact that factors such as HT, HM and PE are significant predictors of Behavioral Intention to Google Classroom usage. Importance-Performance Map Analysis (IPMA) showed that Habit is an important factor in determining actual usage (UB) compared to the Behavioral Intention. On the other hand, Amadin FI [9], shows that FC is the strongest significant predictor on the BI towards the acceptance and use of Google Apps for Education, also it has a positive relationship of the constructs PE, HM, SI on the BI. Other path coefficients which are respectively for technology acceptance (TA), EE, HT with BI have low values, hence they show insignificant relations.

Venktash et al [7] propose the following hypotheses for model UTAUT2:

H1: Performance Expectancy (PE) has a positive effect on Behavioral Intention (BI) when using Google Classroom.

H2: Effort Expectancy (EE) has a positive effect on Behavioral Intention (BI) when using Google Classroom

H3: Social Influence (SI) has a positive effect on Behavioral Intention (BI) when using Google Classroom

H4: Facilitating Conditions (FC) has a positive effect on Behavioral Intention (BI) when using Google Classroom

H5: Hedonic Motivation (HM) has a positive effect with Behavioral Intention (BI) when using Google Classroom.

H6: Habit (HT) has a positive effect on Behavioral Intention (BI) when using Google Classroom.

H7: Habit (HT) has a positive effect relationship with actual Use Behavior (UB) of Google Classroom.

H8: Behavioral Intention (BI) has a positive effect with actual Use Behavior (UB) of Google Classroom.

\subsection{Relationship Proposed for Constructs}

There is lots of empirical evidence affirming that EE, is significantly linked to intention in using a new technology directly and indirectly via its impact on PE [10]. Venkatesh, Bala [11] indicated that EE is a direct determinant of perceiving usefulness (PU). Bervell et al [12] in the study of Technology Acceptance Research in higher education discussed the significant contribution of effort expectancy (EE) in influencing performance 
expectancy (PE). Since the effort expectancy from the survey represents ease of use, in the context of our study is affirmed that ease of use of Google Classroom impacts in user performance. Mark et al [13] report in their study of Habits of LMS usage that peer effects (similar to SI) have a strong positive relationship with habit. Relationships of Habit with PE, EE are proposed by Limayem et al [14].

Regarding students' perceptions of using Google Classroom, Kumar et al [2] in the modified model UTAUT2, confirmed that HT has a positive significant relationship with EE towards Google Classroom usage intention and with Effort Expectancy (EE) towards Google Classroom usage intention. The UTAUT2 model was implemented because it is considered a powerful model to explore the factors that affect behavioral intentions in using Google Applications for Education [9], [15]. Based on the above research studies, we propose the following hypotheses to explore the relationship between following constructs:

H9: Effort Expectancy (EE) has a positive effect with Performance Expectancy (PE)

H10: Social Influence (SI) has a positive effect with Habit (HT)

H11: Habit (HT) has a positive effect with Performance Expectancy (PE)

H12: Habit (HT) has a positive effect with Effort Expectancy (EE)

In the proposed alternative model has been assumed that there are 7 constructs respectively: Effort expectancy (EE), Performance Expectancy (PE), Social Influence (SI), Habit (HT), Hedonic motivation (HM), Behavioral Intention (BI), Use Behavior (UB). The constructs and the respective indicators of each construct are presented in the appendix A1. The connections between the constructs are given in the figure 2 .

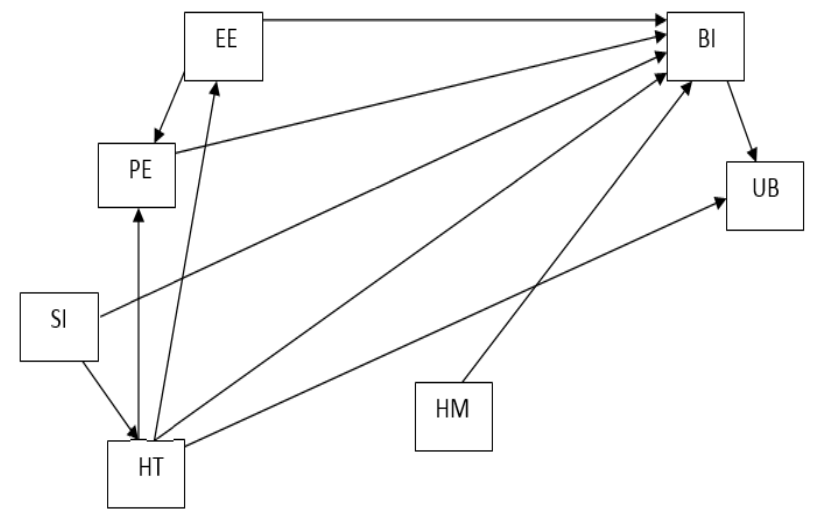

Figure 2. The alternative model

The aim of this paper is the expansion of the conceptual model UTAUT2, as described above (Figure 2), and the relationship between habit, effort expectancy, performance expectancy, social influence. More specifically, has been explored the connection of construct habit with effort expectancy, performance expectancy, in order to understand the habit's behavior. This will be particularly useful to higher education policy makers. It is important to understand the factors that have the most impact in using the Google Classroom for the current and future situation in Albanian universities. In order to evaluate the alternative model, has been used the recently developed techniques in PLS-SEM including Plspredict and IPMA.

\section{Materials and Methods}

The data of this study were collected from 4 universities in Albania. In these universities, due to the COVID-19 pandemic, the Google Classroom platform has been adopted to substitute the face-to-face teaching. The survey included 528 students of bachelor degree, from 18 years old till 21 years old. They completed the online survey voluntarily and the data were collected using the Google form. The survey was completed at the end of the semester end of May-beginning of June. Questions of the survey are taken from AL Maroof et al [16], Jakkaew and Hemrungrote (3) and for the UB construct are adopted by Kumar JA (2), Janossy [17] and are incorporated in the model UTAUT2, that are described in detail in appendix A1. All variables are measured based on a 1-5 likert scale, from "Strongly Disagree" to "Strongly Agree". The software SmartPLS version 3.2.9 is used to analyze the connections between the constructs.

\subsection{PLS-SEM}

Structural equation modelling is one of the most salient studies methods across a variety of fields [18]. Many SEM techniques have been developed, but the most used in various fields is partial least squares structural equation modeling PLS-SEM [18], because it evaluates complex models with many constructs, indicator variables, without imposing conditions regarding the distribution of data [19].

PLS -SEM can be used both for explanatory and predictive research [20]. PLS-SEM with latent constructs is explained by two groups of equations that are (i) measurement model and (ii) the structural model. The measurement model is determined by the connections of construct (latent variable) and its indicator variables, while structural model is determined by the connections between the constructs. When constructs have functions as independent variable they are known as exogenous latent variable and when they have functions as dependent variable they are known as endogenous latent variables [18],[21],[22].

\subsection{Measurement Model}

Firstly when evaluated the measurement models, it is 
necessary to determine whether the constructs' indicators are reflectively or formatively [23]. Reflective constructs indicate that relationships (path) go from the construct to the indicator, so changes in the construct are expected to be reflected in changes in all of its indicators.

Specifically, our study is based on behavioral intentions to use Google Classroom (BI) and based on previous studies, this concept has been operationalized by a reflective measurement model [24]. Are needed to investigate both the reliability and validity reflective measurement model [21]. The measures reliability includes indicator evaluation reliability, internal consistency reliability whereas the validity includes the evaluation of convergent and discriminant validity. It's necessary that loadings, which are correlations of the indicators with their respective latent variables should have values greater than 0.7 to provide satisfactory indicator reliability [19]. To test internal consistency reliability is considered Cronbach's alpha $(\alpha)$ and composite reliability (CR). The formula Cronbach's alpha is calculated on the basis of the indicator variance-covariance matrix [21] whereas composite reliability (CR) is calculated based on the indicator loading estimates [25]. Despite of which of the two indicators will be used, their values must be greater than 0.7 [26]. Average Variance (AVE) extract the amount of variances captured by the indicators in relation to the sum of the variance due to the measurement error. The lower bound of the value of AVE must be at least 0.5 indicating that the construct explains at least 50 per cent of the variance of its indicators [27]. Discriminant validity shows that two different constructs representing different concepts are empirically distinct. There are two guiding criteria for discriminant validity: Fornell-Larcker criterion [28] and Heterotrait-Monotrait Ratio (HTMT) [29]. Fornell-Larcker criterion affirms that: construct's AVE should be greater than its squared correlation with any other construct. To obtain empirical evidence for discriminant validity, Information System (IS) scholars should examine the heterotrait-monotrait (HTMT) ratio of correlations that is defined as the mean value of the indicator correlation across constructs relative to the (geometric) mean of the average correlations for the indicators measuring the same construct. To obtain empirical evidence for discriminant validity is needed the heterotrait-monotrait (HTMT) ratio of correlations to be lower than 0.85 [29].

\subsection{Structural Equation Model}

Before exploring the structural equation model is needed the evaluation of the collinearity. To estimate collinearity is used the variance inflation factor (VIF) and the values for all predictor constructs must be less than 3 [30]. The VIF estimation is performed because values greater than 3 lead to incorrect estimates of path coefficients of structural equations [31]. The elements that are included in the evaluation of the structural model are: path coefficients and their significance based on $\mathrm{p}$ or t-values, the coefficient of determination $R^{2}$, the effect sizes $\left(\mathrm{f}^{2}\right)$, model's predictive relevance $\left(\mathrm{Q}^{2}\right)$ Plspredict Shmueli G [32] and model comparisons Hair JF [19]. In order to evaluate the testing of structural equation modeling hypotheses which includes the significant relationships and the relevance of significant relationships, is used the bootstrapping technique with 5000 resamples. The evaluation of path coefficients of the structural equations model, which represent the connections between the constructs, is founded by a group of regression equations. Therefore it turns that path coefficients are standardized regression coefficients. Path coefficients must be greater than equal to 0.2 to be significant [18]. The coefficient of determination $R^{2}$ is defined as in-sample predictive power [33] and shows the explained variance for each endogenous construct of exogenous construct. According to Hair JF et al [34] values of $\mathrm{R}^{2} 0.75,0.5,0.25$ are considered as substantial, moderate, and weak respectively. Effect size $\left(f^{2}\right)$ is a measure that shows us how the removal of an exogenous construct affects the $\mathrm{R}^{2}$ value. Values $0.02,0.15,0.35$ represent a small, medium and large effect size of the independent constructs [35].

Model's predictive relevance on endogenous construct is evaluated by $Q^{2}$, where $Q^{2}$ is calculated based on a sample re-use technique (blindfolding procedure) which omits a part of data matrix estimates the model parameters and predicts the omitted part using the estimates.

The smaller the difference between predicted and original values the greater the $\mathrm{Q}^{2}$ and thus the model's predictive accuracy. In order to have acceptable predictive relevance the model must have values of $\mathrm{Q}^{2}$ greater than 0 [27].

\subsection{PIsPredict}

Shmueli et al [36] developed Plspredict, which proposes a way to evaluate a model's holdout-of-sample predictive power (model's out-of-sample predictive power).

The database is split into two parts; (i) the first part is the training sample which is used to evaluate the parameters of the model (for example for path coefficients, loading), and (ii) the second part is the holdout samples. The estimation of model's predictive power consists of the calculation of prediction errors that includes statistics, the mean absolute error (MAE), the mean absolute percentage error (MAPE), and the root mean squared error (RMSE). Since these statistics depend on the scaling of the dependent construct's indicators their interpretation is difficult [32]. To solve this issue are introduced two benchmarks which are respectively: $\mathrm{Q}^{2}$ predict and the linear regression model $(\mathrm{LM}) . \mathrm{Q}^{2}$ predict uses the mean value of the variables in a training sample as predictions of the variables in the holdout sample. Is needed to whether the value of $\mathrm{Q}^{2}$ predict for all indicators of measurement model is greater than 0 , so that the model will provide us with 
appropriate predictive power. The linear regression model (LM) technique predicts the values of indicator variables. To give some insights regarding predictive power are compared the RMSE values of PLS-SEM analysis with LM analysis for each indicator. The comparison will be based on the RMSE indicator as it is considered a "gold standard" for judging predictive power [37]. If the values of RMSE measure by using PLS-SEM, are smaller than the results of RMSE by LM for all indicators, then we have high predictive power from the model. If the values of RMSE measure by PLS-SEM are smaller than the RMSE results by LM for the majority of the indicators then we have medium predictive power from the model. If the values of RMSE measure by PLS-SEM are smaller than the RMSE results by LM for minority of indicators then we have as a result low predictive power of the model, and if the values of RMSE measure obtained with PLS-SEM are greater than the LM results for any indicator, means that the model lacks predictive power [32].

\subsection{Model Comparisons}

Researchers when studying a phenomenon, often faced with alternative explanations which bring alternative models based on the theoretical context, and therefore exploring these models is an advanced step in scientific knowledge [38]. The study will develop a comparison between the proposed alternative conceptual model and the configuration of the Kumar JA model [2] in terms of best performing out-of-sample statistics RMSE [37]. Both models have the same endogenous dependent variable. The model that has the lowest RMSE value will be selected as it is often considered as default for judging predictive power [37].

\subsection{IPMA}

In this study is applied the Importance Performance Matrix Analysis (IPMA) as it shows an important evaluation for studies with a focus on technology acceptance [39]. IPMA analysis for structural equation modeling includes construct importance in the context of predicting the target construct (dependent construct) directly or indirectly related to it and the performance that shows the average values of each latent construct scores where the latter are determined by the indicator data [39]. Construct importance regarding the target constructs is the total effect given as a sum of direct and indirect effect in the structural model [40]. The aim is to define constructs that have high importance and low performance in the target construct because in this way is determined the factor needed to increase the performance [41].

\subsection{Multigroup Analysis (MGA)}

The main idea of multigroup analysis is to test if there are significant differences in terms of path coefficients between the gender groups (male and female) of the target population formed based on the categorical moderator variable (gender) [42]. There are different approaches that use this idea, but in our study are used the permutation procedures [43]. Permutation test uses bootstrap sampling techniques to produce the confidence intervals and $\mathrm{p}$-values. This procedure has the advantage that it is not based on data distribution [44]. Before evaluating the differences between path coefficients of relationships across both groups, is measure the invariance of composite model procedure (MICOM) [45]. MICOM consists of 3 tests that evaluate the invariance of constructs between multiple groups and includes configural invariance, compositional invariance, estimation of the equality of the means of the two groups and evaluation of the equality of the variance of the two groups. If configural and compositional invariance are established we have measurement invariance, and thus we can continue the comparison between groups.

\section{Results}

In table 1 we have summarised the data used in this study. In the study $28.6 \%$ are from the Polytechnic University of Tirana, $24.6 \%$ from the University of Tirana, $10 \%$ from the Medical University of Tirana and $36.7 \%$ from the Alexander Moisiu University. From the total number of students, $36.4 \%$ are male and $63.6 \%$ female. Additionally, we see that $36.4 \%$ of users use an android phone to access Google Classroom, $35.8 \%$ use a smartphone and $27.8 \%$ use a personal computer.

Table 1. Demographic information of respondents

\begin{tabular}{|c|c|c|c|}
\hline Item & Values & Frequency & Percentage \\
\hline \multirow{4}{*}{ Gender } & Male & 192 & $36.4 \%$ \\
\cline { 2 - 4 } & Female & 336 & $63.6 \%$ \\
\hline \multirow{4}{*}{ University } & $\begin{array}{c}\text { Polytechnic } \\
\text { University of Tirana }\end{array}$ & 151 & $28.6 \%$ \\
\cline { 2 - 4 } & University of Tirana & 130 & $24.6 \%$ \\
\cline { 2 - 4 } & $\begin{array}{c}\text { University of } \\
\text { Medicine }\end{array}$ & 53 & $10.0 \%$ \\
\cline { 2 - 4 } & University of Durres & 194 & $36.7 \%$ \\
\hline \multirow{2}{*}{$\begin{array}{c}\text { Access } \\
\text { Google } \\
\text { Classroom }\end{array}$} & Android & 192 & $36.4 \%$ \\
\cline { 2 - 4 } & Smartphone & 189 & $35.8 \%$ \\
\cline { 2 - 4 } & Personal Computer & 147 & $27.8 \%$ \\
\hline
\end{tabular}

\subsection{Measurement Model Assessment}

Using the measurement model are determined the respective constructs and indicators of each construct (indicators and constructs are described in appendix (A1)). To evaluate the measurement model are calculated the statistics of loadings, composite reliability (CR), Cronbach's alpha $\alpha$ and variance extracted (AVE). The results are shown in Table 2. 
Table 2. Measurement model evaluation

\begin{tabular}{|c|c|c|c|c|}
\hline Construct and indicators & Loadings & $\mathbf{C R}$ & $\alpha$ & AVE \\
\hline Performance Expectancy (PE) & & 0.907 & 0.796 & 0.83 \\
\hline PE 1 & 0.926 & & & \\
\hline PE 2 & 0.896 & & & \\
\hline Effort Expectancy (EE) & & 0.877 & 0.793 & 0.704 \\
\hline EE 1 & 0.836 & & & \\
\hline EE 2 & 0.86 & & & \\
\hline EE 3 & 0.821 & & & \\
\hline Social Influence (SI) & & 0.961 & 0.919 & 0.925 \\
\hline SI1 & 0.963 & & & \\
\hline $\mathrm{SI} 2$ & 0.961 & & & \\
\hline Hedonic Motivation (HM) & & 0.955 & 0.905 & 0.913 \\
\hline HM 1 & 0.955 & & & \\
\hline HM 2 & 0.957 & & & \\
\hline Habit (HT) & & 0.878 & 0.794 & 0.712 \\
\hline HT 1 & 0.933 & & & \\
\hline HT 2 & 0.936 & & & \\
\hline HT 3 & 0.624 & & & \\
\hline Behavioral Intention (BI) & & 0.889 & 0.894 & 0.818 \\
\hline BI 1 & 0.903 & & & \\
\hline BI 2 & 0.915 & & & \\
\hline BI 3 & 0.895 & & & \\
\hline Use Behavior (UB) & & 0.719 & 0.719 & 0.781 \\
\hline UB 1 & 0.884 & & & \\
\hline UB 2 & 0.884 & & & \\
\hline
\end{tabular}

Table 3. Discriminant validity of measurement model (Fornell Larcker Criterion and Heterotrait-Monotrait Ratio (HTMT))

\begin{tabular}{|c|c|c|c|c|c|c|c|}
\hline & BI & EE & HM & HT & PE & SI & UB \\
\hline BI & 0.904 & & & & & & \\
\hline EE & $0.606(0.704)$ & 0.839 & & & & & \\
\hline HM & $0.529(0.591)$ & $0.24(0.271)$ & 0.956 & & & & \\
\hline HT & $0.685(0.789)$ & $0.543(0.625)$ & $0.513(0.580)$ & 0.844 & & & \\
\hline PE & $0.654(0.766)$ & $0.639(0.79)$ & $0.339(0.394)$ & $0.527(0.623)$ & 0.911 & & \\
\hline SI & $0.663(0.729)$ & $0.657(0.75)$ & $0.327(0.358)$ & $0.615(0.709)$ & $0.682(0.796)$ & 0.962 & \\
\hline UB & $0.552(0.687)$ & $0.533(0.705)$ & $0.235(0.291)$ & $0.485(0.614)$ & $0.585(0.792)$ & $0.52(0.639)$ & 0.884 \\
\hline
\end{tabular}


From Table 2 it is obvious that all loadings are greater than 0.7 with the exception of HT3 that is 0.624 , which we didn't remove from the study because all other statistics that measure the measurement model were within the acceptable limits. Hence the reliability indicator is satisfactory. The construct facilitating condition has been removed from the study because the respective values of loading, CR, $\alpha$, AVE were not within the acceptable limits. The indicators PE3, PE4, EE4, SI3, HM3 were also removed from the study, because their loading values were much smaller than 0.7 and meaning that all the statistics of the measurable model were not within the acceptable limits (all indicator variables are presented in table A1 in appendix). The values of the composite reliability and $\alpha$ are greater than 0.7 . Specifically for composite reliability they range between 0.877 and 0.961 , while for $\alpha$ the values lie between 0.719 to 0.961 . This means that constructs are reliable. Related to the variance extracted (AVE) values of the constructs they exceed the value 0.5 and range from 0.704 to 0.925 . For discriminant validity is used: the Fornell-Larcker criterion and the Heterotrait-Monotrait Ratio (HTMT). The results of the Fornell Larcker Criterion are shown in Table 3. In the diagonal of table 3 are given the values of the square root of AVE and on the lower triangle are given also the correlations between the constructs. It should be noted that the values of the square root of AVE are greater than the correlations between the constructs. The results of the HTMT criterion are presented in Table 3 in brackets and show that all values are less than 0.85 , so all constructs of the alternative conceptual model representing different theoretical concepts are statistically sufficiently different. According to the results the reflective measurement model constructs show significant evidence to the reliability and validity.

\subsection{Structural Equation Model (SEM)}

After presenting an evaluation of the measurement model statistics which resulted within the acceptable intervals, is evaluated the structural equation modelling. For the structural equation analysis have been evaluated the relationships between constructs of the alternative model. We have evaluated the collinearity using the VIF indicator between independent constructs. The VIF values are presented in table 4 where all values are less than 3.The next steps in evaluating the structural model are: path coefficients and their significance based on $\mathrm{p}$ or t-values, the coefficient of determination $R^{2}$, the effect sizes $\left(\mathrm{f}^{2}\right)$ (See figure 3$)$, model's predictive relevance $\left(\mathrm{Q}^{2}\right)$, Plspredict [32]

Table 4. Inner variance inflation factor (VIF) values.

\begin{tabular}{|c|c|c|c|c|c|c|c|}
\hline & BI & EE & HM & HT & PE & SI & UB \\
\hline BI & & & & & & & 1.882 \\
\hline EE & 2.093 & & & & & & \\
\hline HM & 1.389 & & & & & & \\
\hline HT & 2.077 & 1.385 & 1 & & 1 & & 1.882 \\
\hline PE & 2.191 & 1.385 & & & & & \\
\hline SI & 2.479 & & & & & & \\
\hline UB & & & & & & & \\
\hline
\end{tabular}

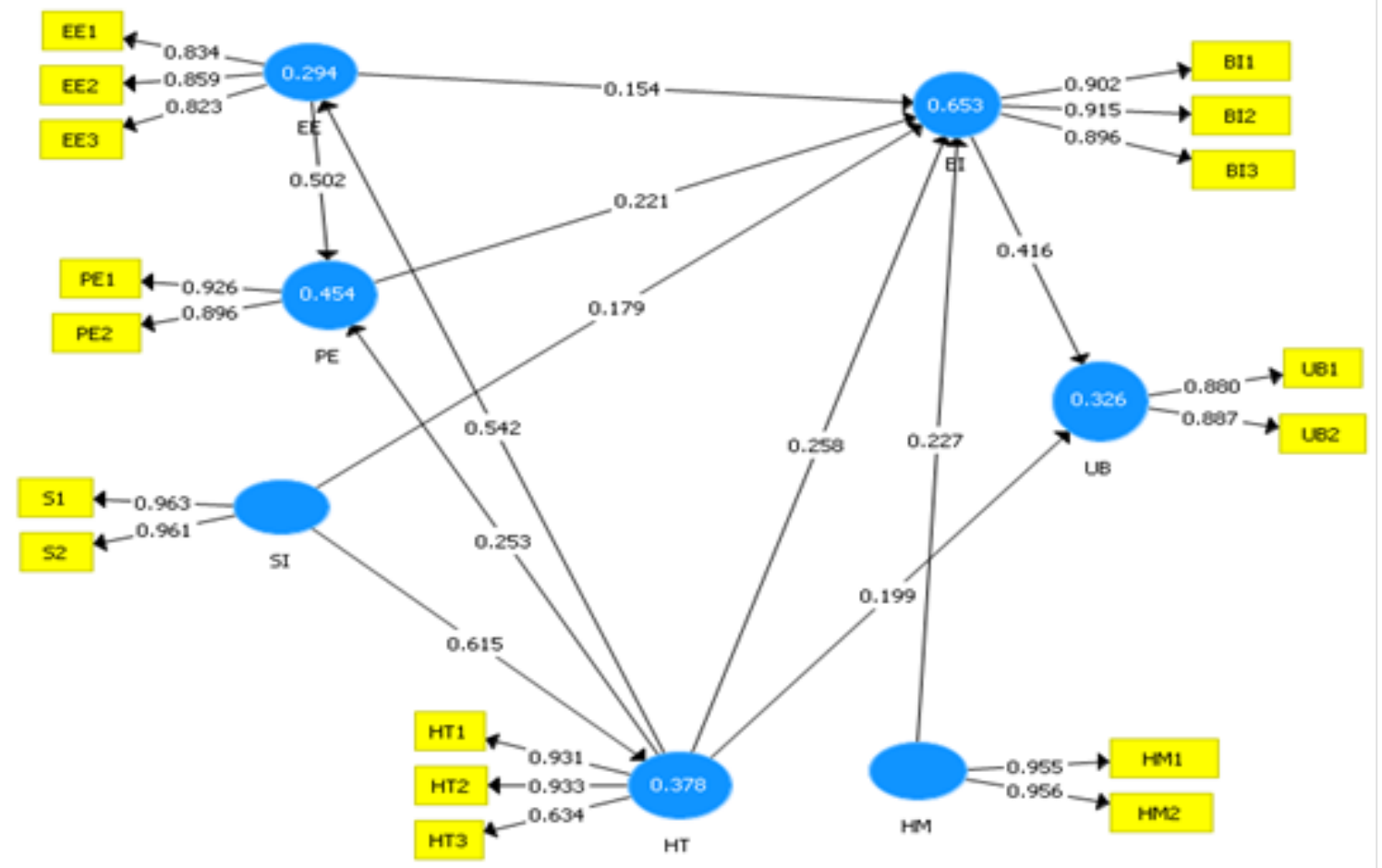

Figure 3. Path coefficients of structural model 
Table 5. Estimation of structural model

\begin{tabular}{|c|c|c|c|c|c|c|}
\hline Hypothesis & Path coefficients & T-Statistics & P-Values & $\mathbf{2 . 5 \%}$ & $\mathbf{9 7 . 5 \%}$ & Effect size $\boldsymbol{f}^{\mathbf{2}}$ \\
\hline $\mathrm{BI} \rightarrow \mathrm{UB}$ & 0.416 & 8.084 & 0.000 & 0.316 & 0.518 & 0.137 \\
\hline $\mathrm{EE} \rightarrow \mathrm{BI}$ & 0.154 & 3.928 & 0.000 & 0.074 & 0.227 & 0.032 \\
\hline $\mathrm{HM} \rightarrow \mathrm{BI}$ & 0.227 & 7.62 & 0.000 & 0.167 & 0.284 & 0.107 \\
\hline $\mathrm{HT} \rightarrow \mathrm{BI}$ & 0.258 & 5.859 & 0.000 & 0.175 & 0.348 & 0.093 \\
\hline $\mathrm{HT} \rightarrow \mathrm{EE}$ & 0.542 & 19.407 & 0.000 & 0.487 & 0.595 & 0.416 \\
\hline $\mathrm{SI} \rightarrow \mathrm{HT}$ & 0.615 & 20.138 & 0.000 & 0.555 & 0.672 & 0.607 \\
\hline $\mathrm{HT} \rightarrow \mathrm{PE}$ & 0.253 & 6.00 & 0.000 & 0.17 & 0.332 & 0.083 \\
\hline $\mathrm{HT} \rightarrow \mathrm{UB}$ & 0.199 & 3.713 & 0.000 & 0.093 & 0.301 & 0.031 \\
\hline $\mathrm{PE} \rightarrow \mathrm{BI}$ & 0.221 & 5.344 & 0.000 & 0.141 & 0.303 & 0.064 \\
\hline $\mathrm{EE} \rightarrow \mathrm{PE}$ & 0.502 & 12.285 & 0.000 & 0.422 & 0.582 & 0.326 \\
\hline $\mathrm{SI} \rightarrow \mathrm{BI}$ & 0.179 & 3.905 & 0.000 & 0.088 & 0.269 & 0.037 \\
\hline
\end{tabular}

Table 5 shows the path coefficients, t-statistics, p-value and confidence intervals (Percentile bootstrap 97.5\% confidence level) which gives the statistical importance of the relations between the constructs.

The estimation of path coefficients of the structural equations model, consist of a group of regression equations, and therefore it follows that path coefficients are standardized regression coefficients. The results in Table 5 show that all paths are significantly different from zero to a $5 \%$ significance level because the p-value is below 0.05 for all the constructs connections. This is also confirmed by the fact that the bootstrap percentile confidence interval does not contain the value 0 , hence all hypotheses are supported.

Our results show a positive significant relation of performance expectancy $(b=0.221, p<0.05)$, effort expectancy $(b=0.154, p<0.05)$, social influence $(b=$ $0.179, \mathrm{p}<0.05)$, hedonic motivation $(\mathrm{b}=0.227, \mathrm{p}<0.05)$, habit $(\mathrm{b}=0.258, \mathrm{p}<0.05)$ in relation to behavioral intention. Therefore these are significant constructs predictors of behavioral intention to use Google Classrooms. We find that the construct that has the greatest impact on BI is HT. Behavioral intention $(b=0.416, p<0.05)$, habit $(b=0.199, p<0.05)$ has a positive significant relation on use behavior with the stronger predictor being $\mathrm{BI}$. Latent variable $\mathrm{EE}(\mathrm{b}=0.502$, $\mathrm{p}=0.000$ ) is a strong significant predictor of PE. SI $(\mathrm{b}=0.615, \mathrm{p}=0.000)$ is a strong predictor in determining the habit of students. HT has a significant effect $(b=0.542$, $\mathrm{p}=0.00$ ) with $\mathrm{EE}$, whereas $\mathrm{EE}$ has a significant effect $(b=0.253, p=0.00)$ with PE. The value of $R^{2} 0.653$ shows us that $65.3 \%$ of the variance of behavioral intention to use Google Classrooms, is explained by performance expectancy, effort expectancy, social influence, hedonic motivation, habit.

Table 6 gives respectively the values of $\mathrm{R}^{2}$ for $\mathrm{EE}$ (0.294), HT (0.378), PE (0.454), UB (0.326) considered as moderate values. Table 5 shows the values of $\mathrm{f}^{2}$ (effect size) for each relation of the structural equation. As shown in Table 5, EE, HM, HT, PE, SI have a weak size effect on BI with values $0.032,0.107,0.093,0.064,0.037$ respectively. On the other hand $\mathrm{BI}$ has a weak size effect $(0.137)$ in UB.

Table 6. Coefficient of determination $\mathrm{R}^{2}$

\begin{tabular}{|c|c|c|}
\hline Construct & R Square & R Square Adjusted \\
\hline BI & 0.653 & 0.65 \\
\hline EE & 0.294 & 0.292 \\
\hline HT & 0.378 & 0.377 \\
\hline PE & 0.454 & 0.452 \\
\hline UB & 0.326 & 0.324 \\
\hline
\end{tabular}

Table 7 has the values of $\mathrm{Q}^{2}$. The results in table 7 show that the values of $\mathrm{Q}^{2}$ for all constructs are greater than 0 meaning that the conceptual alternative model has predictive relevance.

Table 7. Predictive relevance values $\mathrm{Q}^{2}$

\begin{tabular}{|c|c|c|c|}
\hline & SSO & SSE & $\mathbf{Q}^{2}=(\mathbf{1 - S S E} / \mathbf{S S O})$ \\
\hline BI & 1584 & 753.097 & 0.525 \\
\hline EE & 1584 & 1276.058 & 0.194 \\
\hline HM & 1056 & 1056 & \\
\hline HT & 1584 & 1160.7 & 0.267 \\
\hline PE & 1056 & 663.951 & 0.371 \\
\hline SI & 1056 & 1056 & \\
\hline UB & 1056 & 791.23 & 0.251 \\
\hline
\end{tabular}

\subsection{Plspredict Results}

Here is inspected the model's out-of-sample predictive power by using the PLSpredict procedure. Firstly is verified whether all construct indicators have a value of $\mathrm{Q}^{2}$ predict greater than 0 , so that the model will have predictive relevance. From table 8 is shown that all construct indicators have a value of $\mathrm{Q}^{2}$ predict greater than 0 , 
so the model has predictive relevance. Secondly are compared the values of prediction errors in the context of RMSE obtained with the PLS-SEM method, if they give lower values than the prediction errors RMSE is obtained according to the LM method. From table 8 we find that all indicators produce lower prediction errors.

Table 8. Plspredict evaluation of indicators

\begin{tabular}{|c|c|c|c|}
\hline & $\begin{array}{c}\text { RMSE } \\
\text { (PLS-SEM) }\end{array}$ & Q $^{2}$ predict & $\begin{array}{c}\text { RMSE } \\
\text { (LM) }\end{array}$ \\
\hline EE2 & 0.676 & 0.215 & 0.687 \\
\hline EE1 & 0.763 & 0.419 & 0.821 \\
\hline BI3 & 0.786 & 0.361 & 0.828 \\
\hline BI2 & 0.797 & 0.511 & 0.834 \\
\hline PE2 & 0.81 & 0.205 & 0.842 \\
\hline PE1 & 0.817 & 0.426 & 0.845 \\
\hline UB2 & 0.846 & 0.228 & 0.861 \\
\hline BI1 & 0.857 & 0.429 & 0.873 \\
\hline UB1 & 0.861 & 0.448 & 0.874 \\
\hline HT1 & 0.862 & 0.395 & 0.924 \\
\hline HT2 & 0.863 & 0.434 & 0.942 \\
\hline EE3 & 0.871 & 0.181 & 0.975 \\
\hline HT3 & 0.998 & 0.143 & 1.001 \\
\hline
\end{tabular}

The evaluations with PLS-SEM shows that the differences between the values of RMSE are reflected in the indicators EE3, HT2, HT1 which are 0.871, 0.863, 0.862 respectively compared to the values of these indicators in LM that are $0.975,0.942,0.924$.

\subsection{Model Comparisons}

Here is made a comparison of the two models in the context of Plspredict regarding the evaluation of the construct level of the RMSE prediction error. The comparative model is more complex because it includes more connections compared to the alternative model (connection of the hedonic motivation construct with the constructs effort expectancy, habit, performance expectancy) (See figure 4). For all constructs the alternative model produces lower predictive errors constructs (RMSE) compared to the model under consideration (See Table 9). The differences in the RMSE values of the constructs for the two models, are more visible for the EE, and PE factors. The preference for the alternative model is also justified by the fact that models that are more complex (number of estimated parameters) often generalize poorly to new datasets [46], [47].

|Table 9. Plspredict for model comparison

\begin{tabular}{|c|c|c|c|}
\hline Model I & RMSE & Model II & RMSE \\
\hline BI & 0.699 & BI & 0.762 \\
\hline EE & 0.826 & EE & 0.978 \\
\hline HT & 0.793 & HT & 0.864 \\
\hline PE & 0.822 & PE & 0.948 \\
\hline UB & 0.876 & UB & 0.947 \\
\hline
\end{tabular}

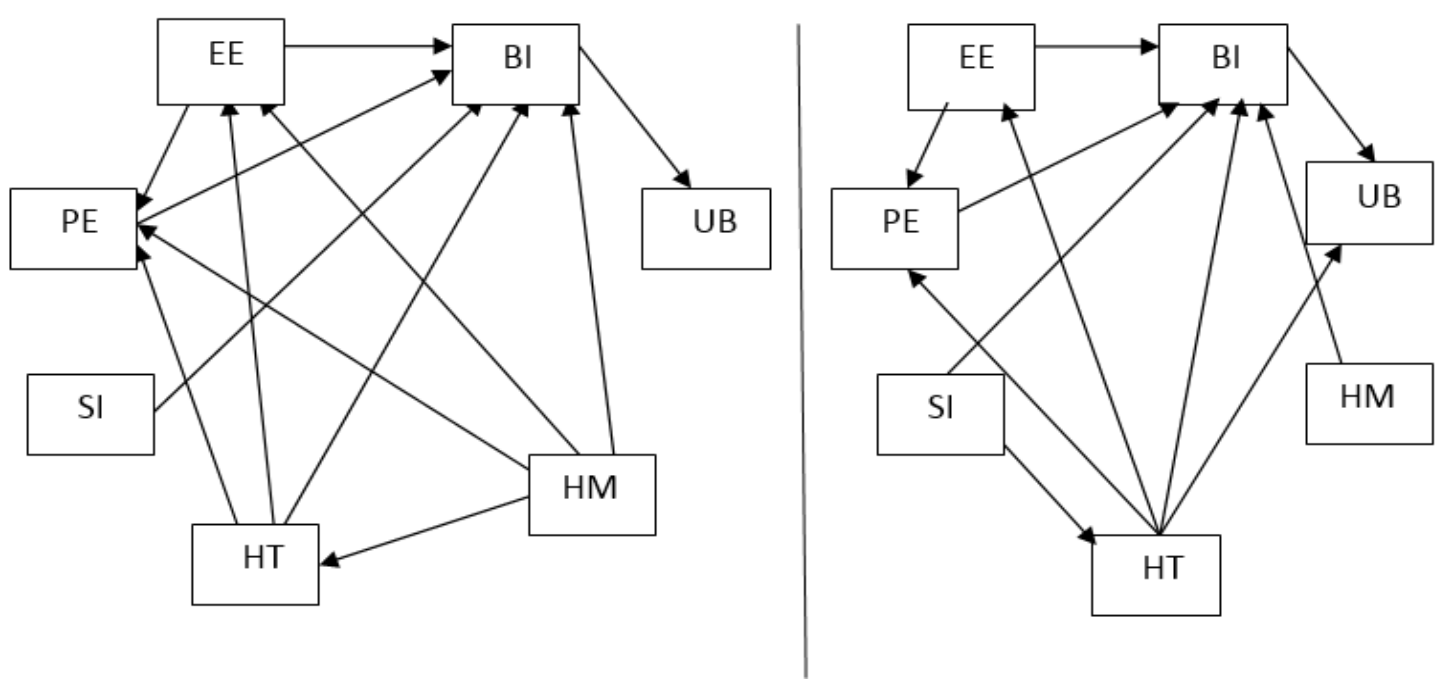

Figure 4. Comparative model and alternative mode 


\subsection{IPMA Results}

Using IPMA we analyze which of the latent variables of the target construct has a relatively high importance [39]. Here, we consider BI and UB as target construct. In tables 10 and 11, we show the importance, and the performance of each latent variable in relation to the target construct.

Table 10. IPMA results for the construct BI

\begin{tabular}{|c|c|c|}
\hline Construct & Importance & Performance \\
\hline EE & 0.339 & 72.475 \\
\hline HM & 0.213 & 29.032 \\
\hline HT & 0.468 & 46.961 \\
\hline PE & 0.245 & 67.117 \\
\hline SI & 0.431 & 57.483 \\
\hline
\end{tabular}

From the results shown in table 10 the variable HT has the greatest importance in relation to $\mathrm{BI}$, with a value of 0.468 , but in terms to performance it has a lower value than the average of the overall performance which is 54.61 .

As our primary aim, is improving performance of the habit factor, thus increasing the performance of the target construct BI. SI is the second factor that has greatest importance with respect to BI with a value of 0.431 and higher performance than the average with a value of 57.43 . The performance values of the factors $\mathrm{EE}$ and $\mathrm{PE}$ in $\mathrm{BI}$ are higher than the average performance $(72.475,67.117$ respectively) while the importance values $(0.339,0.245)$ are lower than the average import value (0.3392).

The results from Table 10 are also represented by the graph in the figure 5, which shows the performance values of all constructs on the $y$ axis and their importance on the $\mathrm{x}$ axis (for the target construct BI). From this graph we see that HT (in the lower right area) has a high importance but low performance in relation to $\mathrm{BI}$.

In table 11 we present the values of importance, performance of each latent variable (factor) in relation to the target construct which in this case is use behavior (UB).

Table 11. IPMA results for the construct BI

\begin{tabular}{|c|c|c|}
\hline Construct & Importance & Performance \\
\hline BI & 0.354 & 49.842 \\
\hline EE & 0.12 & 72.475 \\
\hline HM & 0.075 & 29.032 \\
\hline HT & 0.338 & 46.961 \\
\hline PE & 0.087 & 67.117 \\
\hline SI & 0.249 & 57.483 \\
\hline
\end{tabular}

From these results, we conclude that the latent variable BI with a value of 0.354 has the greatest importance in relation to $\mathrm{UB}$, but in relation to performance it has a lower value than the average of the overall performance (which is 53.81). So the aim is to improve the performance of the BI factor, increasing the performance of the target construct UB. Habit is the second in importance in relation to UB with a value of 0.338 and with a performance value $(46,961)$ lower than the average performance. The performance values of EE and PE and SI factors are higher than the average performance, which are $(72.475,67.117,57.483$ respectively). As can be seen from the graph in the lower right area is BI, which has a high importance but a low performance in relation to the target construct UB. (See figure 6)

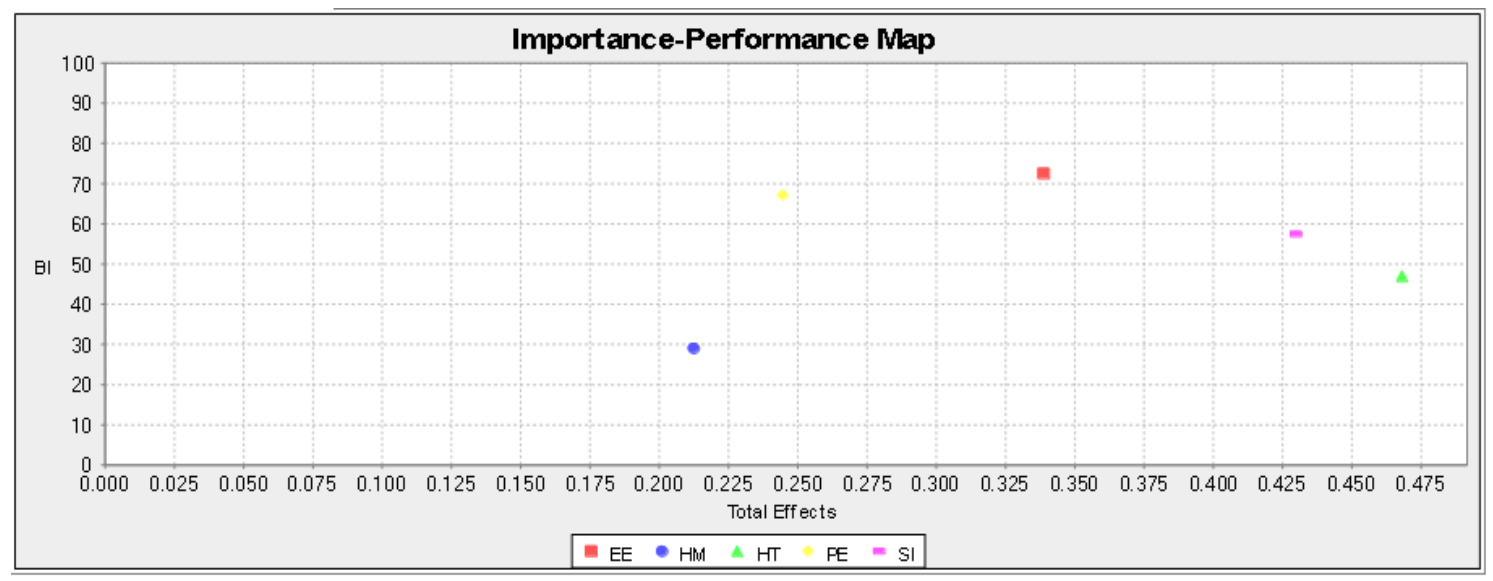

Figure 5. IPMA for Behavioral Intention 


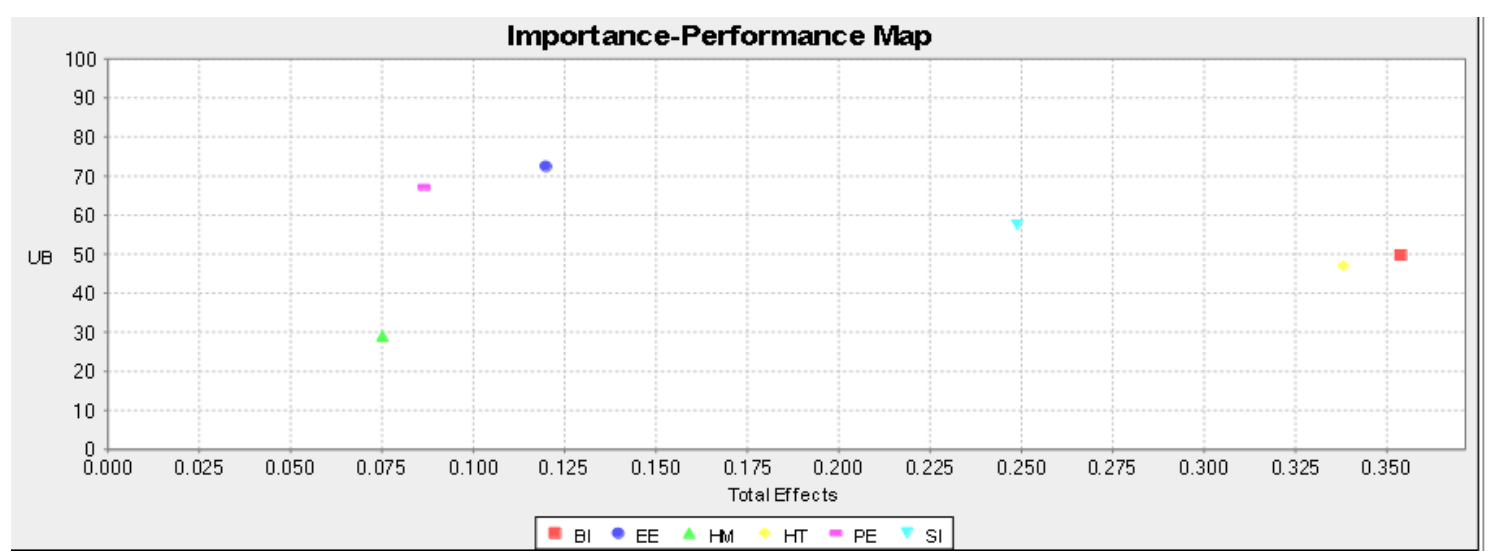

Figure 6. IPMA for Use Behavior

Table 12. Path coefficients permutation mean difference.

\begin{tabular}{|c|c|c|c|c|}
\hline Hypothesis & $\begin{array}{c}\text { Path Coefficients } \\
\text { Male }\end{array}$ & $\begin{array}{c}\text { Path Coefficients } \\
\text { Female }\end{array}$ & $\begin{array}{c}\text { Path Coefficients } \\
\text { Permutation Mean Difference }\end{array}$ & Permutation p-Values \\
\hline $\mathrm{BI} \rightarrow \mathrm{UB}$ & 0.521 & 0.371 & -0.001 & 0.168 \\
\hline $\mathrm{EE} \rightarrow \mathrm{BI}$ & 0.224 & 0.085 & -0.001 & 0.105 \\
\hline $\mathrm{EE} \rightarrow \mathrm{PE}$ & 0.442 & 0.56 & 0.004 & 0.17 \\
\hline $\mathrm{HM} \rightarrow \mathrm{BI}$ & 0.25 & 0.197 & -0.003 & 0.416 \\
\hline $\mathrm{HT} \rightarrow \mathrm{BI}$ & 0.298 & 0.252 & 0.003 & 0.627 \\
\hline $\mathrm{HT} \rightarrow \mathrm{EE}$ & 0.536 & 0.544 & 0.004 & 0.903 \\
\hline $\mathrm{HT} \rightarrow \mathrm{PE}$ & 0.33 & 0.182 & -0.001 & 0.098 \\
\hline $\mathrm{HT} \rightarrow \mathrm{UB}$ & 0.11 & 0.224 & -0.001 & 0.303 \\
\hline $\mathrm{PE} \rightarrow \mathrm{BI}$ & 0.169 & 0.276 & 0.006 & 0.226 \\
\hline $\mathrm{SI} \rightarrow \mathrm{BI}$ & 0.12 & 0.212 & -0.006 & 0.34 \\
\hline $\mathrm{SI} \rightarrow \mathrm{HT}$ & 0.655 & 0.581 & 0 & 0.259 \\
\hline
\end{tabular}

\subsection{Multigroup Analysis (MGA) Results}

Here we test the influence of the variable gender on the relationships included in our alternative model. We have previously performed MICOM procedures, (see Appendix A2) where the configural and compositional invariance are established. Furthermore we perform permutation procedure which aims to compare the path coefficients of the two gender groups that are respectively females and males of all target population. The results in table 12 show the path coefficients of each group, path coefficients permutation mean difference, permutation $\mathrm{p}$ - values.

Regarding the effect of (moderator) gender, we find that in all connections p-value is greater than 0.05 , which means that this moderator has no effect on the path coefficients of the two gender groups.

\section{Conclusions}

The emergence of using Google Classroom resulted urgent due to the occurrence of COVID-19 pandemic. This platform was adopted in all Albanian universities and the study of the factors that influence its use were a new research avenue for Albanian education. Our study proposes a framework that integrates the connections of all constructs with BI and HT connections with $\mathrm{EE}, \mathrm{PE}$, the connection of SI with HT in UTAUT2 model using data from Google Classroom's users. This study is useful in theoretical and methodological context. According the methodological context is useful as it uses advanced techniques recently developed in PLS-SEM which include, Multigroup analysis, Plspredict, IPMA, and model comparisons. Regarding the theoretical side it points out that all constructs PE, EE, SI, HT and HM have a significant positive impact on the behavioral intention of students towards Google classroom. Furthermore, the habit created while using Google Classroom, is the factor that has the most important impact on the definition of BI. Additionally, this result is further verified by the IPMA analysis. Hence the frequent use of Google Classroom by students becomes a habit for them and affects positively the use of Google Classroom in the future. BI is the most important significant predictor in Use behavior to Google Classroom. Regarding the connection of EE with PE, it is reported that effort expectancy is an important factor in determining performance expectancy. Therefore the ease of operation of students with Google Classroom has an 
impact on the usefulness of Google Classroom. In the continuation of other connections, Social influence has a strong influence on Habit to use Google classroom. An important result becomes from the connection of HT with EE from where it is shown that HT has a strong influence on the definition of EE, thus it implies that: when learning in Google Classroom becomes a habit then it is easily used. Regarding the effect of moderator gender in the permutation procedure, we find out that this moderator has no influence on any of the model connections. Another important outcome from this study is that results related to the model comparisons, showing that the alternative model compared to the Kumar, and Bervell model, generates lower values of prediction errors represented by RMSE statistics, thus manifesting a higher predictive power and generalize to other samples.

This study has limitations, among which is the sample size. In order to generalize our results is needed to include in our survey every university in Albania. In this study has not been considered the role of user's age in model connections, but this is something that we plan to investigate further in future work. The use of Google Classroom by staff should also be evaluated further. Additionally, we will explore the relationship between hedonic motivation and EE, PE, SI, as well as analyzing the effect of the moderator university in our results.

\section{Appendix}

\section{A1. Here is presented the full questionnaire developed by the authors Jakkaew P, Hemrungrote S (2017), completed by 528 students from 4 universities of Albania.}

\author{
Questionnaire/Items \\ Performance Expectancy (PE) \\ 1. I find Google Classroom useful in this course of math (PE1) \\ 2. Using Google Classroom enables me to achieve course related tasks more quickly \\ (downloading notes, assignment submission, etc.) (PE2) \\ 3. Using Google Classroom increases my learning productivity (PE3) \\ 4. If I use Google Classroom, I will increase my chances of passing the course (PE4) \\ Effort Expectancy (EE) \\ 1. It is easy for me to become skillful at using Google Classroom (EE1) \\ 2. I find Google Classroom easy to use (EE2) \\ 3. Learning to operate Google Classroom is easy for me (EE3) \\ 4. My interaction with Google Classroom is clear and understandable. (EE4) \\ Social Influence (SI) \\ 1. My friends who are important to me think that I should Participate in Google \\ Classroom. (SI1) \\ 2. My pears who influence my behavior think that I should Use Google Classroom. \\ (SI2) \\ 3. Other people whose opinions I value prefer that I Use Google Classroom. (SI3) \\ Facilitating Conditions (FC) \\ 1. I have the resources necessary to participate in Google Classroom (internet \\ smartphone etc.) (FC1) \\ 2. I have the knowledge necessary to participate in Google Classroom (FC2) \\ 3. I can get help from others when I have difficulties while using Google Classroom \\ (FC3)
}

Hedonic Motivation (HM)

1. Using Google Classroom is fun, compared to traditional classroom. (HM1)

2. Using Google Classroom is enjoyable, compared to traditional classroom (HM2)

3. Using Google Classroom is entertaining, compared to traditional classroom (HM3)

Habit (HT)

1. Using Google Classroom has become a habit for me (HT1)

2. Using Google Classroom has become natural to me (HT2)

3. Using Google Classroom is addictive (HT3)

Behavioral Intention (BI)

1. I intend to continue using Google Classroom in the future (BI1)

2. It is worth to recommend the Google Classroom for other students (BI2)

3. I plan to continue to use Google Classroom frequently (BI3)

Use Behavior (UB)

1. I use Google Classroom for writing quizzes and submitting assignments behavior (UB1)

2. I use Google Classroom to interact with online materials, peers and instructor (UB2)
Source

(Jakkaew P, Hemrungrote S)

(Jakkaew P, Hemrungrote S)

(Jakkaew P, Hemrungrote S)

(Jakkaew P, Hemrungrote S)

(Jakkaew P, Hemrungrote S)

(Al-Maroof RAS, Al-Emran M)

(Jakkaew P, Hemrungrote S)

(Jakkaew P, Hemrungrote S)

(Jakkaew P, Hemrungrote S)

(Jakkaew P, Hemrungrote S)

(Jakkaew P, Hemrungrote S)

(Jakkaew P, Hemrungrote S)

(Jakkaew P, Hemrungrote S)

(Jakkaew P, Hemrungrote S)

(Jakkaew P, Hemrungrote $\mathrm{S}$ ) (Jakkaew P, Hemrungrote S) (Jakkaew P, Hemrungrote S)

(Jakkaew P, Hemrungrote S) (Jakkaew P, Hemrungrote S) (Jakkaew P, Hemrungrote S)

(Jakkaew P, Hemrungrote S) (Al-Maroof RAS, Al-Emran M) (Jakkaew P, Hemrungrote S)

(Kumar JA, Bervell B)

(Kumar JA, Bervell B) 


\section{A2. MICOM Table}

\begin{tabular}{|c|c|c|c|c|c|c|c|c|}
\hline $\begin{array}{c}\text { Full Measurement } \\
\text { Invariance }\end{array}$ & & Yes /No & Yes /Yes & Yes /No & No/Yes & $\mathrm{No} / \mathrm{No}$ & Yes /Yes & $\mathrm{No} / \mathrm{No}$ \\
\hline \multirow{2}{*}{$\begin{array}{c}\text { Equal } \\
\text { Variance } \\
\text { Assessment }\end{array}$} & $\begin{array}{c}\text { Confidence } \\
\text { interval }\end{array}$ & $\begin{array}{c}{[-0.243} \\
0.226]\end{array}$ & $\begin{array}{c}{[-0.305} \\
0.295]\end{array}$ & $\begin{array}{c}{[-0.238} \\
0.233]\end{array}$ & $\begin{array}{c}{[-0.217} \\
0.204]\end{array}$ & {$[-0.313 ; 0.319]$} & $\begin{array}{c}{[-0.228} \\
0.21]\end{array}$ & {$[-0.368 ; 0.349]$} \\
\hline & $\begin{array}{c}\text { Original } \\
\text { differences }\end{array}$ & 0.304 & 0.176 & 0.366 & 0.202 & 0.504 & 0.185 & 0.371 \\
\hline \multirow{2}{*}{$\begin{array}{c}\text { Equal } \\
\text { Mean } \\
\text { Assessment }\end{array}$} & $\begin{array}{c}\text { Confidence } \\
\text { interval } \\
\end{array}$ & $\begin{array}{c}{[-0.167 ;} \\
0.169]\end{array}$ & $\begin{array}{c}{[-0.183 ;} \\
0.169]\end{array}$ & $\begin{array}{c}{[-0.175} \\
0.169]\end{array}$ & $\begin{array}{l}{[-0.18} \\
0.171]\end{array}$ & {$[-0.179 ; 0.165]$} & $\begin{array}{c}{[-0.183 ;} \\
0.171]\end{array}$ & {$[-0.166 ; 0.156]$} \\
\hline & $\begin{array}{c}\text { Original } \\
\text { differences }\end{array}$ & -0.064 & -0.129 & 0.077 & -0.265 & -0.203 & -0.176 & -0.171 \\
\hline $\begin{array}{c}\text { Partial } \\
\text { Measurement } \\
\text { Invariance } \\
\end{array}$ & & Yes & Yes & Yes & Yes & Yes & Yes & Yes \\
\hline \multirow{2}{*}{$\begin{array}{l}\text { Compositional } \\
\text { Invariance }\end{array}$} & $5.0 \%$ & 1 & 0.997 & 1 & 0.996 & 0.999 & 1 & 0.997 \\
\hline & $\begin{array}{c}\text { Original } \\
\text { Correlation }\end{array}$ & 1 & 1 & 1 & 0.996 & 1 & 1 & 0.998 \\
\hline $\begin{array}{c}\text { Configura-tional } \\
\text { Invariance }\end{array}$ & & Yes & Yes & Yes & Yes & Yes & Yes & Yes \\
\hline Constructs & & BI & $\mathrm{EE}$ & HM & HT & $\mathrm{PE}$ & SI & UB \\
\hline
\end{tabular}

\section{REFERENCES}

[1] S. Lonn, S.D. Teasley, "Saving time or innovating practice: Investigating perceptions and uses of Learning Management Systems," Computers and Education, 2009, doi:10.1016/j.compedu.2009.04.008.

[2] J.A. Kumar, B. Bervell, "Google Classroom for mobile learning in higher education: Modelling the initial perceptions of students," Education and Information Technologies, 2019, doi:10.1007/s10639-018-09858-z.

[3] P. Jakkaew, S. Hemrungrote, The use of UTAUT2 model for understanding student perceptions using Google Classroom: A case study of Introduction to Information Technology course, 2017, doi:10.1109/ICDAMT.2017.7904962.

[4] M. Fishbein, I. Ajzen, Beliefs, attitude, intention, and behavior, Strategies of Change: Persuasive Communication, 1975, doi: $10.2307 / 2065853$.

[5] F.D. Davis, "Perceived usefulness, perceived ease of use, and user acceptance of information technology," MIS Quarterly: Management Information Systems, 1989, doi: $10.2307 / 249008$.

[6] V. Venkatesh, M.G. Morris, G.B. Davis, F.D. Davis, "User acceptance of information technology: Toward a unified view," MIS Quarterly: Management Information Systems, 2003, doi: $10.2307 / 30036540$.

[7] V. Venkatesh, J.Y.L. Thong, X. Xu, "Consumer acceptance and use of information technology: Extending the unified theory of acceptance and use of technology," MIS Quarterly: Management Information Systems, 2012, doi:10.2307/4141 0412 .

[8] D.H. Qendraj, E. Xhafaj, A. Xhafaj, E. Halidini, "Ranking the Most Important Attributes of using Google Classroom in online teaching for Albanian Universities: A Fuzzy AHP
Method with Triangular Fuzzy Numbers and Trapezoidal Fuzzy Numbers," Advances in Science, Technology and Engineering Systems Journal, 2021, doi:10.25046/aj060134.

[9] F.I. Amadin, A.C. Obienu, R.O. Osaseri, "Main barriers and possible enablers of Google apps for education adoption among university staff members," Nigerian Journal of Technology, 2018, doi:10.4314/njt.v37i2.18.

[10] V. Venkatesh, F.D. Davis, "Theoretical extension of the Technology Acceptance Model: Four longitudinal field studies," Management Science, 2000, doi:10.1287/mnsc.46. 2.186.11926.

[11] V. Venkatesh, H. Bala, "Technology acceptance model 3 and a research agenda on interventions," Decision Sciences, 2008, doi:10.1111/j.1540-5915.2008.00192.x.

[12] B. Bervell, I.N. Umar, "Validation of the UTAUT model: Re-considering non-linear relationships of exogeneous variables in higher education technology acceptance research," Eurasia Journal of Mathematics, Science and Technology Education, 2017, doi:10.12973/ejmste/78076.

[13] K.P. Mark, Y.Y. Chan, D.R. Vogel, "Antecedents of information systems habit in sporadic use of learning systems: Personalization and peer effects," in Proceedings Pacific Asia Conference on Information Systems, PACIS 2012, 2012.

[14] M. Limayem, S.G. Hirt, C.M.K. Cheung, "How habit limits the predictive power of intention: The case of information systems continuance," MIS Quarterly: Management Information Systems, 2007, doi:10.2307/25148817.

[15] F.J. Rondan-Cataluña, J. Arenas-Gaitán, P.E. Ramírez-Correa, "A comparison of the different versions of popular technology acceptance models a non-linear perspective,” Kybernetes, 2015, doi:10.1108/K-09-2014-01 84.

[16] R.A.S. Al-Maroof, M. Al-Emran, "Students acceptance of google classroom: An exploratory study using PLS-SEM approach," International Journal of Emerging Technologies 
in Learning, 2018, doi:10.3991/ijet.v13i06.8275.

[17] J. Janossy, "Proposed Model for Evaluating C/LMS Faculty Usage in Higher Education Institutions," MBAA International, 2008.

[18] F. Ali, S.M. Rasoolimanesh, M. Sarstedt, C.M. Ringle, K. Ryu, "An assessment of the use of partial least squares structural equation modeling (PLS-SEM) in hospitality research," International Journal of Contemporary Hospitality Management, 2018, doi:10.1108/IJCHM-10-20 16-0568.

[19] J.F. Hair, J.J. Risher, M. Sarstedt, C.M. Ringle, When to use and how to report the results of PLS-SEM, European Business Review, 2019, doi:10.1108/EBR-11-2018-0203.

[20] J. Henseler, G. Hubona, P.A. Ray, "Using PLS path modeling in new technology research: Updated guidelines," Industrial Management and Data Systems, 2016, doi:10.1108/IMDS-09-2015-0382.

[21] J.F. Hair, M. Sarstedt, L. Hopkins, V.G. Kuppelwieser, Partial least squares structural equation modeling (PLS-SEM): An emerging tool in business research, European Business Review, 2014, doi:10.1108/EBR-10-2013-0128.

[22] L. Amaliana, Solimun, A.A.R. Fernandes, Nurjannah, "Efficiency of parameter estimator of various resampling methods on warppls analysis," Mathematics and Statistics, 2020, doi:10.13189/ms.2020.080501.

[23] C.M. Ringle, M. Sarstedt, R. Mitchell, S.P. Gudergan, "Partial least squares structural equation modeling in HRM research," International Journal of Human Resource Management, 2020, doi:10.1080/09585192.2017.1416655.

[24] J. Benitez, J. Henseler, A. Castillo, F. Schuberth, "How to perform and report an impactful analysis using partial least squares: Guidelines for confirmatory and explanatory IS research," Information and Management, 2020, doi:10.1016/j.im.2019.05.003.

[25] T.K. Dijkstra, J. Henseler, Consistent partial least squares path modeling, MIS Quarterly: Management Information Systems, 2015, doi:10.25300/MISQ/2015/39.2.02.

[26] J. Henseler, C.M. Ringle, R.R. Sinkovics, "The use of partial least squares path modeling in international marketing," Advances in International Marketing, 2009, doi:10.1108/S1474-7979(2009)0000020014.

[27] W.W. Chin, The partial least squares approach for structural equation modeling., 1998.

[28] C. Fornell, D.F. Larcker, "Evaluating Structural Equation Models with Unobservable Variables and Measurement Error," Journal of Marketing Research, 1981, doi: $10.2307 / 3151312$.

[29] J. Henseler, C.M. Ringle, M. Sarstedt, “A new criterion for assessing discriminant validity in variance-based structural equation modeling," Journal of the Academy of Marketing Science, 2014, doi:10.1007/s11747-014-0403-8.

[30] J.M. Becker, C.M. Ringle, M. Sarstedt, F. Völckner, "How collinearity affects mixture regression results," Marketing Letters, 2015, doi:10.1007/s11002-014-9299-9.

[31] R. Grewal, J.A. Cote, H. Baumgartner, "Multicollinearity and measurement error in structural equation models: Implications for theory testing," Marketing Science, 2004, doi:10.1287/mksc.1040.0070.

[32] G. Shmueli, M. Sarstedt, J.F. Hair, J.H. Cheah, H. Ting, S. Vaithilingam, C.M. Ringle, "Predictive model assessment in PLS-SEM: guidelines for using PLSpredict," European Journal of Marketing, 2019, doi:10.1108/EJM-02-2019-018 9.

[33] E.E. Rigdon, "Rethinking Partial Least Squares Path Modeling: In Praise of Simple Methods," Long Range Planning, 2012, doi:10.1016/j.lrp.2012.09.010.

[34] J.F. Hair, C.M. Ringle, M. Sarstedt, "PLS-SEM: Indeed a silver bullet," Journal of Marketing Theory and Practice, 2011, doi:10.2753/MTP1069-6679190202.

[35] J. Cohen, Statistical power analysis for the behavioural sciences. Hillside, NJ: Lawrence Earlbaum Associates, 1988, doi:10.1111/1467-8721.ep10768783.

[36] G. Shmueli, S. Ray, J.M. Velasquez Estrada, S.B. Chatla, "The elephant in the room: Predictive performance of PLS models," Journal of Business Research, 2016, doi:10.1016/j.jbusres.2016.03.049.

[37] P.N. Sharma, G. Shmueli, M. Sarstedt, N. Danks, S. Ray, "Prediction-Oriented Model Selection in Partial Least Squares Path Modeling," Decision Sciences, 2018, doi:10.1111/deci.12329.

[38] P.N. Sharma, M. Sarstedt, G. Shmueli, K.H. Kim, K.O. Thiele, "PLS-based model selection: The role of alternative explanations in information systems research," Journal of the Association for Information Systems, 2019, doi:10.17005/1.jais.00538.

[39] C.M. Ringle, M. Sarstedt, Gain more insight from your PLS-SEM results the importance-performance map analysis, Industrial Management and Data Systems, 2016, doi:10.1108/IMDS-10-2015-0449.

[40] M. Hair, J. F., Hult, G. T. M., Ringle, C. M., \& Sarstedt, “A Primer on Partial Least Squares Structural Equation Modeling (PLS-SEM). Thousand Oaks," Sage, 2013.

[41] C. Höck, C.M. Ringle, M. Sarstedt, "Management of multi-purpose stadiums: Importance and performance measurement of service interfaces," International Journal of Services, Technology and Management, 2010, doi:10.1504/IJSTM.2010.034327.

[42] L. Matthews, J. Hair, R. Matthews, "PLS-SEM: The holy grail for advanced analysis," Marketing Management Journal, 2018

[43] W.W. Chin, J. Dibbern, An Introduction to a Permutation Based Procedure for Multi-Group PLS Analysis: Results of Tests of Differences on Simulated Data and a Cross Cultural Analysis of the Sourcing of Information System Services Between Germany and the USA, 2010, doi:10.1007/978-3-540-32827-8 8 .

[44] M. Sarstedt, J. Henseler, C.M. Ringle, "Multigroup analysis in partial least squares (PLS) path modeling: Alternative methods and empirical results," Advances in International Marketing, 2011 , doi:10.1108/S1474-7979(2011)0000022012.

[45] J. Henseler, C.M. Ringle, M. Sarstedt, "Testing 
measurement invariance of composites using partial least squares," International Marketing Review, 2016, doi:10.1108/IMR-09-2014-0304.

[46] I.J. Myung, "The importance of complexity in model selection," Journal of Mathematical Psychology, 2000, doi:10.1006/jmps.1999.1283.

[47] M. Forster, E. Sober, "How to tell when simpler, more unified, or less ad hoc theories will provide more accurate predictions," British Journal for the Philosophy of Science, 1994, doi:10.1093/bjps/45.1.1. 